\title{
DESVIO DO PENSAMENTO \\ E DA CULTURA NAS NOVLÍNGUAS (KLEMPERER, ORWELL, CANETTI)
}

Claudine Haroche

Claudine Haroche

Diretora de Pesquisa

no CNRS.

Tradução

Leandro Siqueira
RESUMO: A Língua do Terceiro Reich (LTI), descrita por Victor Klemperer, assim como a Novlíngua, criada por George Orwell em 1984, revelam as condições e as formas de desvio do pensamento e da cultura. A ambiguidade, a falsificação e a mentira, de um lado, e o empobrecimento intencional da língua, de outro, levam à ignorância e à supressão deliberada das nuanças, e mesmo tornam impossível a liberdade de pensamento. Duras, insensíveis, brutais e propagadoras do terror, as novlínguas são as línguas de facções e clichês. Habitado pelo medo, o indivíduo é condenado por elas a uma insegurança psíquica profunda e contínua, promovida e alimentada pela organização.

Palavras-chave: Terceiro Reich LTI, novlínguas, organização, facções, clichê, terror.

ABSTRACT: Distortion of thought and culture in newspeaks (Klemperer, Orwell, Canetti). Third Reich language LTI described by Klemperer as well as newspeak created by Orwell in 1984 reveal conditions and ways thought and culture are twisted. Ambiguousness, falsification, lying on one side, deliberate impoverishment of language on the other lead to ignorance, intentional suppression of nuances - impeding if not making impossible freedom of thought. Hard, lacking any sensitivity, spreading terror, newspeak is a language of clan and cliché. Filled with fear, individual is condemned to a deep and permanent psychicological insecurity, produced and fueled by organization.

Keywords: Third Reich LTI, Newspeak, organization, clan, cliché, terror. 
$\mathrm{N}$ o final dos anos 1980, nas entrevistas com Philippe Roth, Aharon Appelfeld confidencia: "como quase todos os outros jovens sobreviventes do Holocausto, de início eu tentei escapar de mim mesmo, de minhas lembranças e escrever sobre uma vida que não seria a minha". ${ }^{1}$ Trinta anos mais tarde, em uma entrevista dedicada à língua, Appelfeld conta como, em 1946, chegando à Palestina, encontrou-se "sem linguagem": ele não fala mais o alemão, nem fala ainda o hebreu, que se vê obrigado a aprender. "Fale hebreu!", repetiam-lhe constantemente. Ele se sente, neste momento, confrontado com uma língua que lhe parece dura, uma língua em que as palavras que designam as atividades mais banais do cotidiano “soam como ordens... Ir! Dormir! Arrumar!”. Uma língua que vai lhe intimar a ordem de esquecer, de reprimir, de apagar seu passado, sua língua materna, sua personalidade. ${ }^{2}$ Mais ainda: o hebreu, uma língua outra que a sua, graças à emigração, vai lhe permitir o desenraizamento, viver no presente, se desfazer daquela língua que foi a sua, mudar de personalidade e ter, assim, um futuro. Appelfeld rememora então a ambivalência de sua relação com o alemão. Recorda-se de ter “crescido em uma família judia assimilada, na qual o alemão era considerado como um tesouro. Não era apenas uma língua, era uma cultura, uma cultura que reverenciávamos piedosamente". ${ }^{3}$

Ao desviar-se do pensamento e da cultura na qual cresceu, privado psiquicamente da confiança, da segurança e da inocência dadas pela língua materna, a língua alemã vai traí-lo e, ao se revelar mortífera, termina por privá-lo de si mesmo. " "Era a minha língua materna, mas era também a língua dos assassinos", escreverá Appelfeld, relatando que, ao estar apartado dela, aprenderá,assim como os outros, a manter-se em silêncio por medo, repressão e também por recusa, para continuar a viver. Sobre esta língua materna, à qual teve de renunciar, não sem dilaceramento, reflete: "um homem que perde sua língua materna está mutilado (infirme) para a vida" ${ }^{5}$ Do que foi ele privado? Da inocência, de um sentimento de segurança perdido para sempre. No que consiste esta mutilação (infirmité)? Na destruição dos mecanismos de defesa.

“A língua materna”, prossegue Appelfeld, "você não a fala, ela flui": ${ }^{6}$ em sua origem, ela nasce na evidência do contato fusional, do amor sem limite e sem

\footnotetext{
${ }^{1}$ Philippe Roth, Parlons travail (Shop talk. A writer and his colleagues at work, 2001) Folio, Gallimard, 2004, Aharon Appelfeld, 1988, p.55, p.44. (N. da T.: As referências deste artigo encontramse, excepcionalmente, por questões técnicas, nos rodapés e não no final do texto.)

${ }^{2}$ Nurith Aviv, D’une langue à l'autre, éditions Montparnasse, carnets nord, 2011, “Aharon Appelfeld", p.16-17.

${ }^{3}$ Roth, Parlons travail, op. cit., p.61.

${ }^{4} \mathrm{O}$ desvio que nos interessa aqui não trata da pureza, mas de uma questão de sentido, de retornar a um sentido distorcido de seu sentido original.

${ }_{6}^{5}$ Aviv, D’une langue à l'autre, op. cit., p.18.

${ }^{6}$ Ibid.
} 
condição: da doçura, da ternura, do bem-estar, do reconforto e da proteção. Os braços da mãe que trazem confiança ao pequeno ser permitir-lhe-ão abraçar o mundo: eles estão no fundamento da própria capacidade de pensar, de sentir e compreender. ${ }^{7}$

Podemos conceber que um indivíduo possa falar sem ter havido uma língua materna? ${ }^{8}$ Qual é, portanto, a relação com a língua materna? Uma relação ao outro, à fala, à escuta, ao mundo que permitirá tornar-se um ser falante, qualquer que seja a língua pela qual o indivíduo se exprimirá mais tarde — seja escolhendo-a, desejando-a, trocando-a por outra (mesmo que se esforce para isso ou seja levado a tal), ou até mesmo sendo forçado.

\section{FAZER SUA OUTRA LÍNGUA MATERNA}

Sobre o hebreu aprendido já adulto, confidencia Appelfeld: "nós escolhemos um punhado de palavras... para nos proteger e nos camuflar", recusando assim a transparência, o desnudamento, a negação da interioridade e de um espaço interior. ${ }^{9}$ Appelfeld rememora, então, a aprendizagem da língua hebraica, revelando que ela o "fez pensar (...), ser econômico de (suas) palavras”, ensinando-o, portanto, a prudência, a circunspecção. Se isto não é a dissimulação, é, ao menos, distância, temporização, reflexão, discernimento, que desta forma o levou “a não intervir demais, a não interpretar demais". ${ }^{10}$ Como se faz de tudo que é estrangeiro, naturalmente se desafiava esta língua outra: procurava-se nela o conforto perdido, demandava-se por proteção, sem se entregar a uma confiança total. Esta língua, continua ele, "parecia estrangeira, não judia, para os nossos ouvidos”, e propõe algo um pouco paradoxal, “o que explica talvez nossa imediata afeição por ela”: pelo distanciamento, pelo exercício da razão, ela nos permitiu reencontrar uma confiança limitada, frágil e incerta nos outros, no mundo e em si mesmo. ${ }^{11}$ Appelfeld afirma que se pode aprender uma outra língua materna e o faz por meio de uma constatação factual e uma decisão racional: "hoje eu não tenho outra língua. O hebreu é minha língua materna”. Mas ele imediata-

\footnotetext{
7 O que tampouco impedirá, no entanto, os pais de amarem uma criança incondicionalmente, procurando antes de tudo preencher por meio desta criança um ideal do "eu" enfraquecido.

${ }^{8}$ Consideremos o caso da criança lobo, nos casos tragicamente menos irreversíveis de hospitalização.

${ }^{9}$ Appelfeld, L'héritage nu, (1994, Beyond Despair) éd. De l'Olivier, 2006. p.40. Sobre esta questão da transparência ver "Les tyrannies de la visibilité" (sob a direção de N. Aubert, Cl. Haroche), Erès, 2011.

${ }^{10}$ Roth, Parlons travail, op. cit., p.54, p.45.

${ }^{11}$ Ibid., p. 55.
} 
mente acrescenta: "é uma língua que eu tenho medo de perder". 12 "Eu sei que eu a aprendi, eu sei também - ao contrário da língua materna inscrita para sempre no mais profundo de mim - que eu posso perdê-la”. Aprender e poder perder, aprender a perder. Aceitar a vulnerabilidade. "Eu sonho, eu escrevo nela. Até este dia, eu tenho o temor de perder esta língua. Às vezes, eu acordo e este hebreu adquirido com tanto sofrimento se esvanece, desparece". ${ }^{13}$

Não foram necessárias mais que algumas linhas para Appelfeld fazer considerações cruciais sobre a língua materna, a fala, o pensamento e a personalidade, descrevendo o que ocorre quando, desviada, ela acarreta a perda da inocência, da confiança, além da perda da fala e do sentido, tornando-se pouco a pouco "uma língua de assassinos". Appelfeld descobre então o papel decisivo do silêncio, da privação de sentido, do non sens, "tudo o que nos chegou durante os anos de guerra estava amontoado em nós, silencioso e cego", ${ }^{14}$ observado como "a incapacidade de traduzir sua experiência e o seu sentimento de culpabilidade se associam para criar o silêncio". ${ }^{15}$ Parece que, daqui em diante, ele não poderia nem falar e nem se calar. Ao discernir diferentes níveis de repressão, diferentes qualidades de silêncio — um silêncio de confiança, de bem-estar, de tranquilidade, de meditação, e outro de desconfiança; ainda, um silêncio de medo e um outro, enfim, de terror — - Appelfeld constata o apagamento, a desaparição da própria possibilidade de profundidade, a negação da interioridade, da verdade interior, observando, então, que “a vida continuava”, mas “vivida na superfície da consciência”. ${ }^{16}$

Completamente opostas à língua materna, as línguas outras que a minha contribuem para esclarecer: aquela que Klemperer, enquanto filólogo, estudou nos cadernos dedicados à LTI (Língua do Terceiro Reich), publicados em 1947, também aquela que Orwell chamou de Novlíngua, em 1949. Sua releitura permite estudar as condições e as formas de desvio do pensamento e da cultura, seus efeitos e suas consequências para o indivíduo singular, sobre sua existência, sua pessoa e sua personalidade.

À proximidade, à doçura e ao calor da língua materna que, para retomar os termos de Appelfeld "flui naturalmente", opõem-se estas línguas duras, insensíveis, que quebram, brutais, que não "fluem": aquelas que aderem apenas ao coletivo, que o promovem, desinteressando-se pela singularidade, quando não

\footnotetext{
${ }^{12}$ Aviv, D’une langue à l'autre, op. cit., p.18. Para uma situação análoga ver: F.Rosenzweig, L'étoile de la rédemption (1921), Seuil, 1982, assim como Lévinas, Éthique et infini, Fayard, 1982 e Emmanuel Lévinas, qui êtes vous ?, de François Poirié, Lyon, La Manufacture, 1987.

${ }^{13}$ Ibid.

14 Appelfeld, L’héritage nu, op. cit., p.38.

${ }^{15}$ Ibid., p.62. Sobre a culpabilidade, ver Primo Lévi, Si c'est un homme (1947), Julliard, 1987, assim como Les rescapés et les naufragés (1986), Gallimard, 1989.

${ }^{16}$ Ibid., p.43.
} 
a apagam: elas colocam o indivíduo efetivamente no passo e no silêncio de sua vida interior. Em grande parte delimitadas, construídas, fabricadas, estas línguas são fixas e paralisadas: a língua da organização (do Terceiro Reich) descrita por Klemperer, assim como a novlíngua criada por Orwell em sua utopia negativa 1984. Tanto uma como a outra ensinam a desconfiança em relação aos outros e impõem a submissão à família ampliada, ou ainda à tribo — restrita — e, ao mesmo tempo, paradoxalmente, ao universo infinito. Estas novlínguas supõem o empobrecimento da língua, da diversidade de significações, de seus conteúdos, conduzindo a uma ignorância deliberada das nuances e até mesmo à sua supressão. Elas desconfiam da interrogação, do questionamento, da inteligência, do pensamento, quando elas não lhes são hostis, fazendo-os objetos de estigmatização. O que havia, assim, levado Appelfeld a notar que na Shoah "não havia lugar para as palavras e para as questões", observando ainda "a trama apertada de numerosos fatos exteriores, de maneira a esconder a verdade interior". ${ }^{17}$

Estas línguas buscam eliminar a singularidade e com ela a originalidade, a criatividade, a fantasia, o jogo, proibindo tanto o contato espontâneo e não controlado com o outro, quanto a relação consigo mesmo. ${ }^{18}$ Elas tendem a desprezar, ignorar, apagar a singularidade, o pensamento e as diferenças, podendo assim levar ao indiferenciado. ${ }^{19}$

\section{LÍNGUA DE CLÃS E DE CLICHÊS}

Ao querer-se transparente, assim como faz a novlíngua, a LTI busca a ambiguidade mínima. No entanto, ela é acompanhada da duplicidade, da mentira e da falsificação da verdade. Não é uma língua em que se pode pensar, nem uma língua em que se pode sonhar, refletir, imaginar, permitindo e encorajando a criatividade. Trata-se de uma língua fria, uma língua quase sempre gelada, capaz de exprimir e de difundir o terror: língua do poder, da dominação, da busca do poder desenfreado e ilimitado, que controla, confina e nega o indivíduo. Habitado pelo medo e pela angústia, o indivíduo é verdadeiramente condenado a uma profunda e contínua insegurança psíquica, provocada e mantida pela organização burocrática, ${ }^{20}$ a menos que, diluído no clã, garantida a segurança

\footnotetext{
${ }^{17}$ Appelfeld, L'héritage nu, op. cit., p.30, p.38.

${ }^{18}$ D. W. Winnicott, Jeu et réalité, L'espace potentiel (1971), 1975, Folio, Gallimard, 2002, em português: O brincar e a realidade. Rio de Janeiro, Imago, 1975; Nietzsche, Le gai savoir, (1882), em português: A gaia ciência, São Paulo, Companhia das Letras, 2001.

${ }^{19}$ Sobre o indiferenciado, ver Castoriadis, La montée de l'insignifiance, Seuil, 1996.

${ }^{20}$ Não é qualquer grupo que apresenta um funcionamento de clã sectário: é necessário bem distinguir os clãs das confrarias, dos círculos tribais, de clãs, hierarquizados no interior segundo tradições, costumes, regras estritas e ancestrais, ou ainda, distinguir de quaisquer minorias ativas. Sobre o funcionamento dos grupos, ver E. Enriquez, que pontua que "todo
} 
— certo tipo de segurança — não tenha renunciado a sua originalidade, sua criatividade e sua individualidade.

Inelutavelmente, o pensamento e a cultura supõem uma parte de singularidade individual. Eles alimentam a sua formação, a sua construção e o seu desenvolvimento. O seu desvio consiste em um uso sistemático da ambiguidade, um relegar, até mesmo um desvio da singularidade, que induz ou impõe o homogêneo, a privação da liberdade, a desapropriação de si, a destruição da singularidade, podendo conduzir à desorientação psíquica, ao desenraizamento, o que havia levado Appelfeld a ressaltar que "a fragmentação em pedaços da personalidade foi uma das formas mais profundas do dano criado pela Shoah". 21 Ao evocar os testemunhos dos sobreviventes, Appelfeld mostra-se sensível a alguns aspectos da sua psicologia, "sua precipitação, sua dificuldade de se exprimir e a sua completa falta de introspecção”: 22 é necessário, sem dúvida, chegar à conclusão que a negação da liberdade interior pode explicar esta insegurança psíquica.

A preocupação com a transparência encoraja o controle do vocabulário, permite a concisão das palavras, incita à instantaneidade. A vontade de eliminar as palavras - aquelas que, por não terem um uso precisamente definido, poderiam suscitar a reflexão, a interrogação — conduz a um empobrecimento deliberado do vocabulário. Klemperer observa em várias oportunidades esta pobreza resultante da tentativa de supressão das nuances e da presença contínua dos mesmos clichês. Aparentemente contrários, imobilidade e movimento parecem agora sinônimos: o movimento não define mais o livre funcionamento da língua, ele agora se exerce contra o indivíduo. Longe de partir do movimento o ato de fazê-lo livre de seus atos e pensamentos, impõe ao indivíduo o movimento que, doravante, o oprime e o imobiliza. Esta língua que coage o indivíduo ao movimento, ao mesmo tempo, não cessa de lhe impedir toda iniciativa — em suma, um ritmo que lhe seja próprio. ${ }^{23}$

grupo conhece um dia a tentação da "comunidade”, que é assim definida: "por comunidade entendo uma associação voluntária de pessoas (...) querendo trabalhar ou viver em conjunto de maneira intensa e, às vezes, em fusão". Enriquez reforça ainda: "este momento comunitário me parece indispensável para permitir o escoramento de todos os membros do grupo uns sobre os outros e sobre o grupo". Ele evidencia que "por outro lado, quando o grupo se fixa nesta etapa, ele não é mais capaz da menor ação susceptível de recolocar em questão seu equilíbrio. O conformismo dos sentimentos torna-se a regra, a submissão ao grupo idealizada, (...) A única possibilidade. Mais inquietante ainda, o crescimento de uma metáfora comum, aquela de um corpo pleno, sem falhas, sem falta, sem temporalidade (...)" ("La rencontre du groupe. Dialogue entre Didier Anzieu et Eugène Enriquez", Revue Française de Psychanalyse, 3, 1999, p.742.).

${ }^{21}$ Appelfeld, op. cit., p. 50.

22 Ibid., p. 57.

${ }^{23}$ Ver em particular os desenvolvimentos dedicados a "A lógica totalitária”, por Arendt, em Les origines du totalitarisme, Le système totalitaire, (1959) Seuil, 1972. Em português: Origens do 
Tanto na LTI quanto na novlíngua, a rapidez, a velocidade exaltada é efetivamente imposta ao indivíduo, redundando na eliminação do tempo de pensamento e da reflexão, revelando, além disso, e de maneira mais fundamental, o medo do homem que pensa. É, portanto, o movimento que contribui para assegurar a subordinação, a diluição, o apagamento de si no grupo. ${ }^{24}$ Klemperer insiste, em várias oportunidades, sobre o papel da lancinante repetição de clichês que, reforçando a ausência de pensamento, revela bem o papel decisivo do mecânico dos processos e das técnicas de propaganda. O desvio do pensamento é assim ilustrado da forma mais clara possível nesta observação: "se alguém no lugar ‘de heroico e de virtuoso', utiliza durante muito tempo 'fanático', ele terminará por crer verdadeiramente que um fanático é um herói virtuoso e que sem fanatismo não se pode ser um herói”. ${ }^{25}$ O fanatismo faz parte, como sublinha Klemperer, das palavras onipresentes na LTI: "não se quer ser cético, nem liberal e ponderado, não se quer ser veleidoso, como antes... quer-se agir”, mas agir não segundo a inspiração, livre e espontaneamente, mas "submetendo-se às cadências coletivas...". 26

Klemperer sublinha que o movimento é, neste ponto, a essência do nazismo, que se designa como "O movimento", e recorre incessantemente a palavras como "relâmpago”, “ataque”, “raio”,"fulminante”. Todo o vocabulário e ao que este remete (o clima, a atmosfera), é dominado pela vontade de movimento e de ação. A palavra "assalto" (Sturm) está constantemente presente. Fala-se de "seção de assalto”, de "assalto de cavalaria”, de "tropas de assalto”; fala-se, ainda, de "canhões de assalto”, e “o diário de Goebbels se chama o ataque”, ressalta Klemperer, que discerne, enfim, as palavras essenciais da LTI: o heroísmo, o grupo, a relação ao grupo. Na língua do Terceiro Reich é o grupo que fala, jamais o indivíduo.

Toda uma concepção da palavra e da expressão se desenha assim na novlíngua, que Klemperer descreve como uma língua de clã e não do indivíduo, uma língua repleta de clichês, destinada a exprimir a grandeza do grupo, do coletivo, a megalomania do chefe. ${ }^{27}$ "Tudo na LTI era discurso, tudo devia ser arenga, intimidador, inflamador (...) você não é nada, seu povo é tudo”, proclamava assim

\footnotetext{
totalitarismo, São Paulo, Companhia de Bolso, 2012. Ver igualmente H. Meschonnic, Dans le bois de la langue, éd. Laurence Teper, 2009.

${ }^{24}$ Ver Cl.Haroche, L'avenir du sensible, Les sens et les sentiments en question, PUF, 2008, chap.6, "Les mouvements de jeunesse - 1918-1933”. Em português: A condição sensível. Formas e Maneiras de sentir no Ocidente, Rio de Janeiro, Contracapa, 2008.

${ }^{25}$ Klemperer, LTI, la langue du 3ème Reich, p.40.

${ }^{26}$ Ibid., p.291.

27 Ver Georges Sorel citado em Peter Gay, La culture de la haine, Hypocrisies et fantasmes de la bourgeoisie de Victoria à Freud, (1993), Plon, 1997, p.109.
} 
um de seus slogans. Isto significava: "você jamais está sozinho consigo mesmo.... você se encontra sempre diante de seu povo". ${ }^{28}$

Klemperer ainda percebe este desvio do pensamento a propósito da palavra "filosofia”: "ela está na lista dos horrores", nota ele, "ao lado da inteligência e da objetividade". ${ }^{29}$ Assim, a valorização da ação é permanente. A vida se define pela rapidez mecânica, o automático. $\mathrm{O}$ indivíduo isolado não tem mais nenhum valor, existe apenas como engrenagem de um sistema, de uma máquina. ${ }^{30}$

\section{CONSEGUIR FAZER DA LÍNGUA UMA QUESTÃO DE "LARINGE"}

As observações de Klemperer sobre a língua do Terceiro Reich são ilustradas e ainda reforçadas nos princípios da Novlíngua de Orwell. É a mesma inspiração em questão de vocabulário e de filosofia, e as finalidades buscadas são idênticas: imobilizar a fim de controlar, suprimir assim a hesitação, a dúvida, fabricar a língua e a realidade, delimitá-las e torná-las úteis. “A Novlíngua se diferenciava de quase todas as outras línguas na medida em que seu vocabulário se reduzia em vez de aumentar a cada ano", nota Orwell, e "o que era exigido, antes de tudo por razões políticas, eram palavras curtas no sentido evidente de que podiam ser pronunciadas rapidamente e que despertavam não mais que um mínimo de eco no espírito do indivíduo". ${ }^{31}$ E ele ainda acrescenta que é o anatômico, o orgânico, o automático, o mecânico que se queria privilegiar, procurando fundamentalmente "fazer da linguagem articulada um problema de laringe, sem mais se fazer intervir os centros cerebrais mais elevados". 32

Trata-se ainda de uma língua da transparência, da literalidade, ${ }^{33}$ do clichê, da trivialidade: a liberdade de pensar é eliminada, o jogo com as significações, a criatividade e a imaginação são, doravante, impossíveis aí. Há a criação de novas palavras, de neologismos — o objeto da novlíngua é, efetivamente, obstruir e até mesmo tornar impossível o pensamento solto e o individual.

Algumas passagens de Orwell são bastante reveladoras do empobrecimento da língua e da supressão da riqueza semântica: "independentemente da supressão das palavras claramente heréticas, a redução do vocabulário era considerada como um fim em si, toda palavra que se podia não utilizar, não tinha

\footnotetext{
${ }^{28}$ Klemperer, op. cit., p.49.

29 Ibid., p.40.

30 G. Anders, L'obsolescence de l'homme, (1956), Éditions de l'Encyclopédie des Nuisances, 2001.

31 Orwell, 1984, “The principles of newspeak” (1949), Signet Classics, p.308. Em português: 1984, São Paulo, Companhia das Letras, 2012.

32 Ibid., p.309.

33 Entenda-se bem, não o caso da língua alemã, mas a língua do Terceiro Reich.
} 
mais direito à existência”. ${ }^{44}$ Desta forma, a palavra livre havia perdido a ideia de riqueza imprevisível e inédita: tendia-se agora, na Novlíngua, a significá-la como “desvencilhado de”, "purgado de”, “não obstaculizado por”. A literalidade, a utilidade e a necessidade tinham suprimido o borrão, a imprecisão, as nuances. “A palavra 'livre' existia na Novlíngua, mas podia ser usada apenas em frases como 'o cachorro se desvencilhou de suas pulgas' ou 'este campo foi desvencilhado de suas ervas daninhas". Desde então, não podia mais “ser empregado no seu antigo sentido de 'politicamente livre' ou 'intelectualmente livre', porque as liberdades política e intelectual não existiam mais mesmo como conceitos e estavam, portanto, necessariamente sem nome". ${ }^{35}$ E a conclusão de Orwell é que "uma pessoa crescendo com a Novlíngua como única língua não saberia mais... que livre havia significado outrora 'intelectualmente livre"”. ${ }^{36}$ Além disso, a ambiguidade, a falsificação e a mentira estão, portanto, em oposição a toda forma de autonomia que deixa entrever a quintessência do desvio do pensamento: o que se prima, assegurando assim o exercício da subserviência, é a organização, da qual nada deve poder escapar.

Entretanto, apenas uma concessão a esta subserviência: as exigências da vida cotidiana, quando "era manifestadamente necessário refletir antes de falar”, mas, de imediato, define Orwell, "um membro do Partido ao ter quefazer um julgamento político ou ético devia ser capaz de dar opiniões concretas tão automaticamente quanto uma metralhadora". 37 O ideal requisitado: o automático. Falar como uma metralhadora devia levar a uma transformação profunda e radical da personalidade, acompanhada de uma relação outra com a língua e com seus conteúdos: estes deveriam cortar para sempre a ligação com os braços da mãe que,assegurando a capacidade de amparo (contenance), permitia o funcionamento dos continentes (contenants) e dos conteúdos, condição própria da capacidade de pensar.

\section{TER NOS BRAÇOS, DAR NASCIMENTO Ȧ FALA E AO PENSAMENTO INDIVIDUAL}

Nós gostaríamos de retornar mais uma vez à evocação da língua materna feita por Aharon Appelfeld: “a língua materna”, confidencia ele, "você não a fala, ela flui". 38

\footnotetext{
${ }^{34}$ Orwell, 1984, op. cit., p.300.

${ }^{35}$ Ibid., p.308.

${ }^{36}$ Ibid., p.311.

${ }^{37}$ Ibid., p.308-309.

${ }^{38}$ Appelfeld, in Aviv D'une langue à l'autre, op. cit., p.18. A fluidez que tendia a significar o sangue, a vida, reenvia no presente aos fluxos da sociedade líquida (ver Z. Bauman, Liquid modernity, Cambridge, Polity Press, 2000. Em português: Modernidade líquida, Rio de Janeiro, Zahar, 2012).
} 
O interesse em aproximar os escritos de Appelfeld, Klemperer e Orwell dos trabalhos psicanalíticos de Anzieu e Winnicott fica aqui evidente: o empobrecimento da língua, efetivamente, supõe e reforça a eliminação do jogo crucial nos processos relacionados à emergência e aos desenvolvimentos do pensamento e da cultura. ${ }^{39}$

Nos trabalhos dedicados aos continentes de pensamento, Didier Anzieu afirma que "a criança pequena encontra sua segurança ao estar 'nos braços' de sua mãe". ${ }^{40}$ Ao permitir a confiança em si, os braços da mãe ou, em seu lugar, braços maternos, asseguram e garantem um sentimento de pertencimento, condições mesmas da emergência e do desenvolvimento do pensamento e da língua materna: “é necessário à criança ter sido 'rodeada' por um 'meio' que pensava por ela”, destaca Anzieu. ${ }^{41}$ É preciso observar aqui, de maneira ao mesmo tempo literal e metafórica, as condições de possibilidade de compreender uma questão.

Pelas hipóteses que formulou, no final dos anos 1960, nos trabalhos dedicados aos objetos transicionais fornecidos pelo meio materno, Winnicott nos parece particularmente interessante, na medida em que estes objetos estão profundamente ligados aos funcionamentos dos continentes de pensamento. ${ }^{42}$ Estes continentes permitem, subentendem e desenvolvem de forma efetiva os conteúdos: apenas os braços permitem àquele que é carregado, tido, rodeado, protegido, por sua vez, abraçar o mundo pelo pensamento. Winnicott apreende também o pequeno humano e o desenvolvimento do pensamento pelo movimento, pela atividade: por meio dos fenômenos transicionais que instauram e reforçam as condições de um eu confiante, apreciador, reconhecedor, pensante, falante. É aqui que ele vai elaborar a noção de objeto transicional, que se desenvolve em um espaço igualmente definido como transicional, que a mãe estabelece para a criança entre ela e o mundo. ${ }^{43}$ Este espaço intermediário entre o pensamento, a cultura e o eu

\footnotetext{
${ }^{39} \mathrm{O}$ empobrecimento deve-se hoje à falta de tempo, levando a outra relação com a memória, a tradição, a duração e a história de cada um.

${ }^{40}$ Didier Anzieu, Les contenants de pensée, Dunod, 2003: "La fonction contenante de la peau, du moi et de la pensée: conteneur, contenant, contenir”, p.29. Sobre esta questão do amparo (contenance), ver em particular a referência a Spinoza sobre as raízes corporais do pensamento (p.17).

${ }^{41}$ Ibid., p.29. Sobre estas questões ver a abordagem fundadora de Edwin Strauss, em Du sens des sens. Contribution à l'étude des fondements de la psychologie (1935), éd. Jérôme Million, 2000.

${ }^{42}$ Winnicott, Jeu et réalité, op. cit. Sobre as questões de holding e de handling, ver Winnicott, De la pédiatrie à la psychanalyse (1969) Payot, 1989. Ver igualmente em outra perspectiva Huizinga, Homo Ludens. Essai sur la fonction sociale du jeu, Gallimard, 1938.

${ }^{43}$ Winnicott enfatiza que é no momento do desenvolvimento da pequena criança que se situam estes fenômenos transicionais que vão passo a passo levar da "incapacidade da pequena criança a reconhecer e aceitar a realidade" à "capacidade que ela progressivamente adquirirá de fazê-lo" (Jeu et réalité, op. cit., p.30). Ver Florence Guignard "Réflexions d'une psychanalyste sur l'enfant dans la société d'aujourd'hui” in Marie France Castarède, L'image et la pensée, (éd.) Erès, 2011, que lembra, a propósito do devir deste espaço transicional e
} 
permite construir uma relação com o mundo externo e desenvolver, ao mesmo tempo, um espaço interno a partir da relação ao objeto: Winnicott insiste no fato de que o objeto transicional leva a certo tipo de atividade mental e "assinala a progressão da criança na direção da experiência vivida". 44

Ao alternar entre a proximidade e o afastamento, que se desenrola nos limites e nas bordas apreensíveis, o jogo permite que a criança se desprenda do contato fusional, instaura uma distância de si, o que leva Winnicott a afirmar que "o objeto transicional [é] a primeira posse não eu”. Acrescenta ainda que "no mundo de relação ao objeto, o sujeito autoriza algumas modificações de si". ${ }^{45}$ Desta forma, o jogo vai permitir as atividades de diferenciação, as práticas de discernimento, constituindo uma via de aproximação aos fenômenos psíquicos e sociais que torna possível, assinala Winnicott, "através do objeto transicional o processo que leva a criança a aceitar a diferença e a similaridade”, concluindo que "é na base do jogo que se edifica toda existência experiencial do homem". ${ }^{46}$ Em que a língua materna permite que você se torne uma individualidade, uma personalidade singular? Quando tornada “uma língua de assassinos”, no que ela é suscetível de impedi-lo, de fazê-lo perder as esperanças? Talvez, na medida em que ela suprima o íntimo, em que ela ignore o foro interior, a vida interior, a possibilidade de consciência de cada um.

\section{DOS BRAÇOS DA MÃE AO CORPO DO CLÃ}

Ao permitirem experimentar a confiança em si, um sentimento de identidade, fazendo nascer e desenvolver uma capacidade de responder na medida e de um modo nuançado, os braços, da mãe e dos próximos, protegem, reconfortam, satisfazem assim a necessidade de pertencimento. Esta necessidade está igualmente presente na weltanschauung, tanto na questão das visões de mundo ou na questão das representações coletivas: ${ }^{47}$ quando ela julga este pertencimento ignorado, até mesmo ameaçado em sua integridade, esta weltanschauung é passível de incitar ao sectarismo e à radicalidade, de desviar assim tal necessidade de pertencimen-

potencial, a necessidade de distinguir a extensão contemporânea do espaço virtual. Para Fl. Guignard, "a maior diferença reside na questão da ligação do objeto (...) O virtual propõe uma ilusão real que permite fazer a economia do trabalho psíquico de vínculos e de transformação necessária às boas relações entre o mundo psíquico interno e a realidade exterior (...) A dimensão relacional é aqui implicitamente tratada como uma validade a ser gerida, mais do que como um componente do desenvolvimento psíquico da personalidade e da qualidade da ligação do objeto", p.222-223.

${ }^{44}$ Winnicott, Jeu et réalité, op. cit.,

${ }^{45}$ Ibid., p.33 e p.165.

${ }^{46}$ Ibid., p.30, p.36 e p.126.

${ }^{47}$ Ver em particular o texto de Freud "Sur une weltanschauung”, Nouvelles conférences d'introduction à la psychanalyse (1933), Folio Gallimard, 1989. 
to, de conduzir a um desencadeamento de violência psicológica e psíquica. ${ }^{48}$ A abertura do espírito, a abertura ao mundo supondo o si, sua existência e sua proteção na relação ao outro, exige a capacidade de ultrapassar o medo do outro, indissociável do medo de si, e opõe-se ao fechamento do espírito, dos clãs, das tribos e ao seu medo do outro. Há diferentes formas de responder ao medo, à insegurança psíquica, de se afastar e resistir a isso. Algumas formas de reconforto são relativamente neutras com relação à política e à ideologia. Outras, sem dúvida, o seriam muito menos quanto às suas origens e seus efeitos.

Klemperer tinha destacado a presença insistente da weltanschauung, o seu papel na língua do Terceiro Reich, surpreendendo-se com “o que, na virada do século, era um termo de clãs — weltanschauung — havia-se transformado em palavra mestre da LTI" ${ }^{49}$ A weltanschauung, podendo aparecer no sentido amplo de visões de mundo, horizontes de pensamentos, pode igualmente ser compreendida em um sentido estreito, defensivo, incitando à dobra sobre si e sobre os seus, encorajando o medo do estrangeiro e do outro.

É necessário discernir aqui um estado de espírito e um clima político feito de desconfiança: a visão do mundo reconhecida e imposta pelo coletivo, a weltanschauung, poderia, em certas condições, contribuir para colocar o indivíduo no passo e no silêncio da vida interior: ela então revelaria e induziria a uma transformação radical da personalidade, podendo levar à negação do espaço interior, à destruição da personalidade. Tanto em um como no outro caso, ela satisfaria a necessidade de pertencimento e de proteção. O caráter pernicioso de alguns valores que constroem modelos de comportamento e de sentimento induzidos ou impostos pela comunidade, pelo clã, a radicalidade própria a certos pequenos grupos - o que se designa, às vezes como espírito tribal — é aqui manifesto, opondo-se às diferenças e às nuances nascidas da história e da singularidade individual.

O desvio do pensamento e da cultura tende a estreitar o horizonte de pensamento e de referências, fazendo-se coincidir, e mesmo apagar, a ideia de cultura e de civilização, esquecendo, ou mesmo negando, o valor de toda uma dimensão de universalidade capaz de garantir a ideia de cultura, de proteger a personalidade e um espaço interior em cada um, a própria possibilidade de consciência. Klemperer sublinhou que se a LTI utilizava a palavra weltanschauung, "é que ela encontrava expressa nesta palavra o seu opositor mais importante, segundo ela,o ato de filosofar". Pois, acrescentava ele, o "filosofar é uma atividade da razão, do pensamento lógico, e o nazismo é hostil a ele como ao seu pior inimigo". 50

\footnotetext{
48 Ver "Les mouvements de jeunesse en Allemagne (1918-1933)", op. cit., em particular a passagem dedicada à fusão dos corpos, p.125.

${ }^{49}$ Klemperer, LTI. La langue du 3ème Reich, op. cit., p.193.

${ }^{50}$ Ibid., p.194, p.188-189. Compreende-se aqui a desconfiança que Freud tinha em relação ao
} 
Ora, a passagem de uma língua à outra supõe a abertura de espírito, alguma maleabilidade, a capacidade de fazer face ao medo, de ultrapassá-lo. Esta passagem requer uma margem de liberdade, a aptidão de alternar em relação à identidade e ao diferente, um jogo com o si, um jogo com o outro. Os braços da mãe levam a uma relação específica que permite e desenvolve a língua materna. O corpo do grupo leva a outra relação com a língua, suscetível de encorajar as línguas da organização, das ordens, a língua das certezas. ${ }^{51}$ Estes dois modos de relacionamento com língua e com o outro supõem concepções fundamentalmente diferentes do eu e da personalidade: uma concepção, aberta; a outra, rígida e fechada do eu; e outra ainda, que leva à completa diluição. ${ }^{52}$

Uma weltanschauung rasteira refletiria e reforçaria um espírito de clã, um espírito tribal difuso e generalizado que caracterizam no presente as sociedades contemporâneas, mais e mais complexas, tornadas opacas, desprovidas de mediações. As declarações reivindicando o pertencimento a uma mesma família de pensamento e de espírito não exprimiriam, de maneira alguma, os diferentes pontos de vista dos indivíduos, mas uma estigmatização insidiosa do geral, do abstrato, do filosófico, traduzindo uma concepção do outro, do semelhante, definindo-se pelo similar. O que refletiria o estado de espírito, o plano de fundo da quintessência do desvio do pensamento e da cultura, a qual Klemperer havia notado nos seus cadernos a propósito de uma pequena bandeira em LTI, sobre a qual podia-se ler: "dedique-se a uma atividade manual!" ${ }^{53}$

E é, sem dúvida, um dos maiores desafios das sociedades individualistas, o de proteger a pessoa ${ }^{54}$ do coletivo confundido ou, no sentido menos compreendido, de proteger a pessoa do apagamento das singularidades, suscetível de levar ao indiferenciado. É em um contexto radicalmente diferente, o da Shoah, que Appelfeld havia julgado crucial "tentar fazer falar os acontecimentos através do indivíduo e na sua linguagem, de salvar o sofrimento... do anonimato atroz,

\footnotetext{
lugar dos clãs, das confrarias em Psychologie collective et analyse du moi (1921), Essais de psychanalyse, Payot, 1997.

51 Todavia, estas línguas da certeza coexistem, como Klemperer tinha destacado, com a devoção mística, o que o tinha levado a perguntar-se "em que podia consistir, para os nazistas, a 'devoção a convicções no interior do infinito"” (Ibid. p.193). Sobre o uso que os neorromânticos fizeram da weltanschauung, ver p.194.

${ }^{52}$ Uma diluição que Freud tinha apontado: "o que o eu temo do perigo externo... não se saberia precisar (...) é o transbordamento ou o aniquilamento..." "Le moi et le çà” (1921), Essais de psychanalyse, op. cit., p.273.

${ }^{53}$ Klemperer, op. cit., p.259, “o fato que os judeus sejam ... 'animais de inteligência”, lia-se nos cadernos da LTI, "isto seu sempre foi criticado por Hitler e os seus” (Ibid.).

${ }^{54}$ Este poderia ser também um destes desafios, o de ser capaz de limitar o narcisismo rapidamente confundido com as exigências de reconhecimento e de estima de si dos indivíduos nas sociedades contemporâneas.
} 
de restituir à pessoa seu nome e seu sobrenome, de dar novamente à pessoa torturada a sua forma humana, que lhe foi arrancada". ${ }^{5}$

\section{DA LIBERDADE DE MOVIMENTO AO CARÁTER COMPACTO DAS MASSAS}

Gostaríamos de retornar à Appelfeld, que deplora incansavelmente e diz que a Shoah "vai tão além do que eu posso compreender". Para ele, nós seríamos como que instalados no instituído, acreditando, talvez, encontrar na acumulação e na multiplicação de detalhes históricos a possibilidade de nos dispensar de pensar, de interpretar e teorizar. ${ }^{56}$ Abandonando-nos à fixação e ao imobilismo, poderíamos renunciar à compreensão do vivido e da experiência, escolhendo “[relegar] nossa experiência no dossiê preparado a sua intenção, com a menção "sofrimento infinito desprovido de sentido,". 57

Alguns escritos de sociologia, antropologia e filosofia, ou ainda de psicanálise, discerniram o caráter inquietante, desde o final do século XIX, dos fenômenos totalitários de massa. ${ }^{58}$ Seus autores se mostraram sensíveis ao exercício do poder nos pequenos grupos, no caráter potencialmente ameaçador das relações em algumas comunidades — as fraternidades, em particular.

Os escritos de Weber dedicados às questões sobre os pequenos grupos revelam, em 1919, a inquietante ambiguidade do funcionamento comunitário de alguns círculos para uma sociedade democrática. ${ }^{59}$ Ao dar eco aos funcionamentos destes círculos e da sua atividade comunitária, notam-se os movimentos de juventude que tiveram um papel decisivo para o crescimento do nazismo. Estas fraternidades revelam os elementos essenciais dos processos de formação de uma solidariedade compacta entre os homens.

Ao diferenciar os paradoxais processos feitos de desprezo, de rejeição, de estigmatização e de repulsão, por um lado, e, por outro, de mistificação, de

\footnotetext{
${ }^{55}$ Appelfeld, L'héritage nu, op. cit., p.73. Um breve parênteses para destacar que isto constitui no presente um desafio civilizacional maior. A repetição constante, contínua e lancinante prefigura os efeitos das mídias contemporâneas, o movimento, a aceleração. Sobre estas questões, ver Florence Guignard, "Réflexions d'une psychanalyste sur l'enfant dans la société d'aujourd'hui”, in Marie France Castarède, L’image et la pensée, (éd.) Erès, 2011, que faz uma observação a propósito da "sociedade de hoje e de amanhã... a falta de atividade psíquica continente"; ver igualmente a questão da aceleração contínua e a instantaneidade, L’avenir du sensible, op. cit., Chapitres 11 et 12, “Les états du sensible" e "L'état de fluidité, expérimenter des manières inédites de sentir”.

${ }^{56}$ Appelfeld, L’héritage nu, op. cit., p.90. Sobre o instituído, ver Castoriadis, L’institution imaginaire de la société, Seuil, 1973.

57 Ibid., p.90.

${ }^{58}$ Ver em particular Freud "Psychologie des foules et analyse du Moi”, op. cit.

59 Weber, Le savant et le politique, (1919) Plon, 1959, p.95-96. Em português: Ciência e política: duas vocações, São Paulo, Cultrix, 2011.
} 
atração, de fascinação e de veneração, Weber destaca que estes funcionamentos remetem precisamente à falta, à privação e, até mesmo, à negação de autonomia e de valorização de si. Conclui, então, sobre a ameaça que "a atividade comunitária” pode constituir para a democracia, sublinhando o medo, o pavor, o terror experimentado diante da diferença. ${ }^{60}$ Ele evoca, então, a atmosfera da época a propósito destes pequenos círculos: o apagamento das distâncias, "o contato homem a homem", 61 a procura fusional do corpo a corpo coexistindo com o culto ao chefe. ${ }^{62}$

Após a Segunda Guerra Mundial, numerosos trabalhos abordaram os movimentos de juventude, estas fraternidades que têm, de certa forma, constituído o cadinho do nazismo. Estes grupos, intentando revelar um desejo arcaico de fusão em cada um de seus integrantes, aspiravam a desenvolver, no contato fusional, a ultrapassagem de si, o que consequentemente conduzia a um apagamento de si. 63 "Cada um acordava uma importância considerável ao espírito do grupo, importância confusamente sentida, mas expressa com fervor nas experiências que visavam restaurar os vínculos primitivos”, ${ }^{64}$ destaca Lacqueur. Seus comportamentos surgem como respostas às formas de angústia arcaica, confrontadas às novas formas de vida, de existência, de emancipação potencial. ${ }^{65}$ Diante dos perigos da dispersão, da fragmentação, do isolamento individualista, do possível apagamento de si e das incertezas de um mundo que se transforma, intenta-se refazer o corpo. ${ }^{66}$

Klemperer convidara a ver nas massas um substituto, um elemento desenvolvido no processo corporal da ação dos pequenos grupos, que levava ao apagamento tanto dos limites corporais quanto dos limites psíquicos, podendo, assim, chegar ao indiferenciado. ${ }^{67}$ Mas é Canetti, de fato, ao se dedicar à elucidação das formas de vínculo e de angústia arcaicas, que permite entender este vínculo entre o corpo a corpo fusional nos grupos restritos e o caráter compacto das massas. Em Massa e poder, Canetti nos parece ter esclarecido magistralmente alguns mecanismos do medo. Nascido da fobia do contato inscrita no mais pro-

\footnotetext{
${ }^{60}$ Weber, Économie et Société (1921), Plon, (1971), coll. Agora, 1995, Tome 2, Chapitre 4 "Les relations communautaires ethniques", p.124. Em português: Economia e sociedade: fundamentos da sociologia compreensiva, Brasília, UNB, 2009.

${ }^{61}$ Weber, Le savant et le politique, op. cit., p.96.

62 Weber, Économie et société , op. cit., p.127.

${ }^{63}$ Lacqueur,Young Germany, A History of the German Youth movement, op. cit., p.VII.

${ }^{64}$ Ibid.

${ }^{65}$ Ibid. p.VI.

${ }^{66}$ Pode-se então compreender por que Fromm, o autor de uma célebre obra dedicada a O medo da liberdade (Escape from freedom, 1941), havia redigido um posfácio à obra de Orwell: na obra de Fromm é, efetivamente, a questão central do medo da liberdade, do medo do pensamento, do outro e, fundamentalmente, do medo de si.

${ }^{67}$ Ver Agamben, Ce qui reste d'Auchwitz. L'archive et le témoin. Homo Saccer, Tome III (1998), Rivages Payot, 1999. Em português: O que resta de Auschwitz, São Paulo, Boitempo, 2008.
} 
fundo dos mecanismos arcaicos de defesa, esta fobia permite compreender que a questão do isolamento nas sociedades democráticas e a dimensão compacta das sociedades de massa podem suscitar uma resposta radicalizada e violenta, relembrando a profundidade da necessidade de pertencimento. ${ }^{68}$ "Não há nada mais que o homem tema do que o contato com o desconhecido", salienta este autor, explicando "todas as distâncias que os homens criaram ao redor deles mesmos [como] ditadas por esta fobia do contato". 69

Canetti havia, além disso, percebido outro componente arcaico concomitante a esta fobia do contato: a busca de fusão e de atração que ela poderia oferecer. Distinguiu, então, a existência de funcionamentos paradoxais. Ele havia, de fato, notado que "é apenas na massa que o homem pode ser liberado desta fobia do contato", observando que a massa compacta é a "única situação na qual esta fobia se inverte, tornando-se o seu contrário”. Ele tinha visto nesta inversão a especificidade da massa. "A massa compacta cujos membros se (apinhavam) corpo contra corpo", levava assim à supressão dos limites, das fronteiras corporais e psíquicas: ela era "compacta também na sua desaparição psíquica, isto é,(...) que não se fazia atenção a quem lhes pressionava" ${ }^{70}$ A massa suprimia assim a alteridade e, além dela, a desigualdade: impondo o homogêneo, instaurando o uno corporal e psíquico, esta massa levava ao indiferenciado. Canetti chegava assim a esta conclusão: "quem quer que seja que lhe pressiona, é como se fosse si mesmo. Experimenta-se como se experimenta a si mesmo. De repente, tudo acontece como no interior de um mesmo corpo" ${ }^{71}$

\section{DESPRENDER-SE DA MISTIFICAÇÃO E DA REVERÊNCIA}

É a questão da identidade - individual — e da sua sobrevivência que se coloca aqui. Cada vez mais incerta no presente mundo globalizado, não se construindo mais no quadro da cidadania, a necessidade de pertencimento não cessa de se

\footnotetext{
${ }^{68}$ Arendt insistiu nas origens do totalitarismo, no sistema totalitário, sobre o isolamento e a desolação que aparecem como o inverso da massa compacta. É preciso notar que desolação e massa compacta significam, tanto um quanto o outro, a perda da liberdade de movimento.

${ }^{69}$ E. Canetti, Masse et Puissance (1960), 1966, Tel Gallimard, 1986, p.12, em português: Massa e poder, São Paulo, Companhia das Letras, 2011. Cl. Haroche, "L'individu dans l'illimitation contemporaine", in L'émergence de l'individu entre formes substantielles et droits essentiels, sous la direction d'Annette Ruelle, CRHDI, n.34, 2011, Facultés Universitaires Saint Louis de Bruxelles. ${ }^{70}$ Os filósofos, os sociólogos, os psicanalistas e os antropólogos mostraram-se particularmente sensíveis a este tema da distância e da proximidade entre os indivíduos, distinguindo aqui uma questão fundamentalmente ligada às formas arcaicas de medo e angústia. (Ver em particular: Weber, Economie et société, op. cit., Freud, Psychologie des foules et analyse du moi (1921), Elias, Engagement et distanciation. Contribution à la sociologie de la connaissance (1983), Fayard.

${ }^{71}$ Lefort, L’invention démocratique, Fayard, 1981. Em português: A invenção democrática: os limites da dominação totalitária, São Paulo, Brasiliense, 1987.
} 
intensificar, colocando agora em jogo pequenos grupos e massas, alimentando-se daqui em diante da afirmação identitária e, além disso, reivindicando-a. Pode-se construir uma identidade na massa? "Mais os homens se comprimem com força uns contra os outros", observava então Canetti, "mais eles sentem certamente que eles não têm medo um do outro" ${ }^{72}$

Pode-se construir uma identidade na solidão e no isolamento? “Ainda é possível se identificar a alguém para se afirmar sua própria identidade? (...) seria necessário se constituir por si mesmo, seria necessário poder se inventar sem modelo e sem destinatário certo". ${ }^{73}$ Saber quem se é e ter medo do outro; ou o inverso, saber quem somos confundindo-nos com o outro. Ser constrangido a falar uma língua outra que a sua podia outrora gerar insegurança social e psíquica - tal situação doravante banal, quotidiana, ordinária, poderia talvez contribuir para desprender-se deste medo de si que se acompanha do medo do outro.

Appelfeld evocara a ambivalência de sua relação com a língua alemã, recordando ter "crescido em uma família judia assimilada, na qual o alemão era considerado como um tesouro. Não era apenas uma língua”, confidenciava ele, “era (...) uma cultura que reverenciávamos piedosamente" ${ }^{74}$ Com frequência, o culto e a reverência da língua e da identidade podem inconscientemente trazer efeitos temíveis: o culto tende a ser acompanhado de mistificação — isto quando ele não a engendra, provocando efeitos de rejeição e de exclusão, levando, passo a passo, a uma radicalidade que suscita o ódio. A mistificação coloca de lado toda ideia de nuances, acentua os mecanismos de defesa no que eles possuem de mais rígido, incitando à dureza e, além disso, à crueldade.

Durante muito tempo Appelfeld se mostrou próximo da sensibilidade de Arendt que havia testemunhado "uma ligação inerradicável a uma língua materna única, o alemão”. Ela respondia "ao mesmo tempo de forma desarmada, ingênua e consciente quando se (interrogava) sobre este vínculo” que nada poderia substituir a língua materna. ${ }^{75}$ Derrida observa que ela tinha "guardado sempre esta ligação indefectível e esta familiaridade absoluta (...) como se a experiência do 'sempre' e da fidelidade ao outro como a si mesmo supusesse a fidelidade indefectível à língua". 76

Apenas mais tarde Appelfeld se afastará desta ligação indefectível, quando constatará: “hoje o hebreu é minha língua materna”. ${ }^{77}$ Ele então renunciará a esta eternidade aproximando-se, de certa forma, da inspiração de Rosenzweig,

\footnotetext{
72 Canetti, Masse et Puissance, op. cit., p.12.

${ }^{73}$ Derrida, Le monolinguisme de l'autre, Galilée, 1996, p.95-96.

${ }^{74}$ Roth, Parlons travail, op. cit., p.61.

${ }^{75}$ Derrida, Le monolinguisme de l'autre, op. cit., p.101.

${ }^{76}$ Ibid., p.101-102.

77 Appelfeld, in Aviv, D’une langue à l'autre, op. cit., p.18.
} 
segundo a qual “o 'povo eterno', diferentemente de todos os outros, não começa pela autoctonia (...) O pai de onde é proveniente Israel era um imigrante”. ${ }^{78}$ É, sobretudo, da experiência de Lévinas, “que na língua francesa escreveu, ensinou, viveu quase toda a sua vida, enquanto que o russo, o lituano, o alemão e o hebreu permaneceram suas outras línguas familiares”, que Appelfeld parecerá se aproximar. A ligação à língua materna se faz, para Lévinas, de outro modo, desprovida de solenidade, de sacralidade: "a essência da linguagem é amizade e hospitalidade". 79

Conforme Lévinas, Appelfeld convida assim a pensar a língua materna de maneira diferente: apartado da ideia de língua materna eterna e originária, ele falará de uma familiaridade adquirida. Derrida se perguntará se Lévinas não rompeu "de uma certa maneira, com a raiz ou com a originalidade presumidamente natural ou sagrada da língua materna”, arriscando-se então a responder, "para romper com a idolatria da sacralização, sem dúvida”, afirmando entretanto que “esta língua permanece (...) a fundação do sentido, a inalienável propriedade que se transporta consigo". ${ }^{80}$

É este ponto, sem dúvida, uma das lições essenciais de Appelfeld: aprender com a língua e a identidade a reconhecer misturas e mestiçagens, a desafiar a crença na pureza, nos riscos de mistificação, de reverência, esforçar-se para se desprender. Reconhecer a necessidade de pertencimento e de continuidade na identidade, e não cessar de distingui-la da identificação.

As maneiras de gostar, de se relacionar, de falar e de pensar são profundamente imbricadas. Nascemos na fusão, desprendemo-nos passo a passo pelas palavras, no pensamento. Acontece que esta fusão originária também se perpetua, ancorada no não-pensamento, misturando amargura, hostilidade e ódio, levando à rejeição do outro em nome de uma pureza sagrada. O desvio da língua e da cultura ligado profundamente à supressão dos limites corporais e psíquicos que instauram as massas induzem ao homogêneo, suscetível de conduzir ao indiferenciado.

Recebido em 12/2/2013. Aprovado em 27/3/2013.

Claudine Haroche

clharoche@aol.com

Leandro Siqueira

compulsone@gmail.com

\footnotetext{
${ }^{78}$ F. Rosenzweig, L'étoîle de la rédemption, p.354 e p.355.

${ }^{79}$ Derrida, op. cit., p.109-110.

${ }^{80}$ Ibid., p.111.
} 